\title{
Intoxicación por uso recreativo de 'floripondio', reporte de caso.
}

Sergio Alejandro Barreto ${ }^{1}$, Jacklyn Guzmán ${ }^{2}$, Julio Cesar Gutiérrez ${ }^{3}$

1. Residente de Psiquiatria, Hospital Universitario San Jorge, Facultad de Ciencias de la Salud, Universidad Tecnológica de Pereira, Pereira, Risaralda, Colombia. Correo electrónico: sabp4113@gmail.com

2. Residente de Medicina Interna, Hospital Universitario San Jorge, Facultad de Ciencias de la Salud, Universidad Tecnológica de Pereira, Pereira, Risaralda, Colombia.

3. Médico Psiquiatra, Profesor de posgrado de Psiquiatría, Hospital Universitario San Jorge, Facultad de Ciencias de la Salud, Universidad Tecnológica de Pereira, Pereira, Risaralda, Colombia.

Fecha de Recepción: 14/1/2016

Fecha de Evaluación: 28/1/2016

Fecha de Solicitud de Correcciones: 2/2/2016

Fecha de Aceptación: 28/2/2016

\section{Resumen:}

Hombre de 21 años, con cuadro de envenenamiento por exposición intencionada a planta del género Brugmansia. Ingresó al servicio de urgencias por síntomas neurológicos y neuropsiquiátricos luego de ingesta con fines recreativos de infusión de flores de "floripondio", comúnmente conocido como 'trompeta de ángel'. Requirió observación médica por 48 horas, con buena evolución clínica, y fue dado de alta sin ninguna complicación o secuela neurológica.

Palabras clave: Flores, Envenenamiento.
Poisoning by a flower

Abstract:

A 21 years-old male, with a deliberate poisoning by Brugmansia plant. Admitted to the emergency department for neurological and neuropsychiatric symptoms, after ingestion recreational infusion of flowers "floripondio", commonly referred to as angel's trumpet. He was under medical observation for 48 hours, with clinical improvement and was discharged without any complications or neurological sequelae.

Keywords: Flowers, Poisoning.

\section{Introducción:}

La intoxicación por floripondio (Brugmansia), puede provocar compromiso neurológico severo, generando un síndrome tóxico del que se han descrito pocos casos en la literatura. Se sabe que desde hace algunos años, en nuestro territorio se viene popularizando su uso con fines recreativos en población consumidora de psicoactivos, en una proporción que se desconoce y dado su uso ornamental y la no regulación, es de muy fácil acceso. Por lo anterior se presenta el siguiente caso, con el fin de describir los efectos nocivos de la planta y alertar a la comunidad médica sobre un entidad clínica que debe ser detectada y manejada correctamente.

\section{Caso clínico:}

Hombre de 21 años de edad, residente en la ciudad de Pereira. De escolaridad bachiller, soltero, sin ocupación. Es llevado al servicio de urgencias del Hospital Universitario San Jorge (Pereira- Risaralda) por ingesta de "floripondio".

$\mathrm{Al}$ ingreso con cuadro clínico de 5 horas de evolución, luego de consumo con fines recreativos de infusión de "floripondio", aproximadamente un vaso (Infusión: 4 flores/1 L.); 15 minutos después de la ingesta presentó palpitaciones, respiración rápida, sensación de enajenación de la realidad, con alucinaciones visuales: "veía muchas mariposas, relindas, flotando, de muchos colores, luego dos manos negras, muy grandes que salían de las mariposas y a cogerme", sensación de hinchazón en su cabeza, "temor y desespero", al poco tiempo pérdida de la conciencia y un episodio convulsivo de características tónico clónicas generalizadas, sin relajación de esfínteres, presenciado y reportado por su compañero de consumo.

No hay antecedentes personales ni familiares de importancia, excepto el consumo de cannabis ("cripa") desde los 12 años, en promedio dos cigarrillos por día. El paciente refirió que era la primera vez que tenía contacto con la planta. Al ingreso, anotan: "paciente desorientado, confuso, Glasgow 14/15 Presión arterial: 130/80 mmHg. FC: 75 latidos x min. FR: 20 x min. Temperatura $36^{\circ} \mathrm{C}^{\prime \prime}$.

Es valorado por el servicio de psiquiatría 12 horas luego de su ingreso, evidenciando signos vitales en rango normal, con mucosa oral y piel seca, pupilas isocóricas poco reactivas a la luz con midriasis bilateral $(5 \mathrm{~mm})$, sin otros hallazgos relevantes al examen físico. Al examen mental se encontraba alerta, orientado globalmente, sin alteración en el origen ni el contenido del pensamiento, con amnesias lagunares del evento, conservando juicio de realidad, sin alteraciones en el resto de la evaluación.

Paraclínicos: Hemograma con ligera leucocitosis y neutrofilia, sin anemia y con recuento de plaquetas en rango normal. Azoados y transaminasas en limites normales. Gases arteriales en equilibrio acido base y sin trastorno hidroelectrolítico. Durante su hospitalización recibió manejo solamente con líquidos endovenosos, sin requerir otro tipo de terapias farmacológicas dada la estabilidad clínica; no tuvo tratamiento con carbón activado ni lavado gástrico. Presentó evolución clínica favorable, con resolución completa de sus síntomas. Se le indicó control ambulatorio por psiquiatría y fue dado de alta 48 horas después de su admisión. 


\section{Discusión:}

Desde la antigüedad, la humanidad ha empleado las plantas no sólo con fines alimentarios, sino también con propósitos medicinales y en rituales sagrados. Los indios del valle de Sibundoy (Colombia) usaron con finalidades rituales, en épocas precolombinas, decocciones de algunas especies de Brugmansia genérica y popularmente conocidas como "floripondios" o "floripondas"; entre otros denominaciones autóctonas encontramos las de "borrachero", "huacacachu", "huanta", "chamico", "campanilla", "maiconca", "tonga" y "toa” (1).

Las plantas Brugmansia son consideradas sagradas por los pueblos indígenas de América del Sur, principalmente de Perú y Ecuador, donde son conocidas como wandug o floripondios y se encuentran varias especies: Flores rojas (Brugmansia sanguinea); Flores amarillas (Brugmansia aurea); Flores blancas (Brugmansia candida); Flores de color rosa (Brugmansia suaveolens) (2).

Estas plantas a pesar de ser nativas de América del Sur, están distribuidas mundialmente dado su uso ornamental, encontrándose fácilmente en jardines y parques. El floripondio (Brugmansia), puede provocar compromiso neurológico severo, generando un síndrome tóxico del que se han descrito pocos casos en la literatura. Se sabe que desde hace algunos años en nuestra población se viene popularizando su uso con fines recreativos, en una proporción que se desconoce.

En Alemania, un estudio retrospectivo entre el 2001 y el 2010, mostró que las plantas de los géneros Datura y Brugmansia, fueron las de mayor exposición intencional (abuso), principalmente por adolescentes y adultos jóvenes, y en su mayoría fueron responsables de síntomas moderados o severos, que incluían: coma, apatía, agitación psicomotora, taquicardia, midriasis y severas reacciones psicóticas (3). El año anterior, en Corea del Sur se reportó un caso de delirium, secundario a intoxicación accidental (ingesta en alimentos) con pétalos de trompeta de ángel (Brugmansia), en una mujer de 64 años (4).

En las especies de Brugmansia se han aislado alcaloides del tropano, como hioscina, hiosciamina (1), y principalmente escopolamina y atropina (5). Los alcaloides contenidos en la planta (más notablemente escopolamina) causan inhibición competitiva de los receptores muscarínicos (a nivel central y periférico), lo que resulta en la presentación clásica de un síndrome anticolinérgico visto en intoxicación por 'floripondio' (4). Existen pocos estudios farmacológicos en la literatura sobre estas plantas, algunos estudios in vitro han demostrado la afinidad de los extractos de metanol y agua de la planta para unirse a receptores 5-HT1A, 5- HT2A, 5-HT2C, D1, D2, alfa 1 y alfa $2(6,7)$.

El síndrome anticolinérgico (SA) es una entidad frecuente. Se considera un síndrome secundario a medicamentos o plantas con efecto anticolinérgico, de los que se destacan antihistamínicos, atropina, escopolamina, fenotiazinas y antidepresivos tricíclicos (8). Se caracteriza clínicamente por inquietud, confusión, delirium, alucinaciones, visión borrosa, midriasis, retención urinaria, fiebre, taquicardia, hipertensión, arritmias, colapso cardiorrespiratorio, coma y muerte. El diagnóstico es clínico y deben descartarse otras entidades como hipoxia cerebral, hipercapnia, hipoglicemia, alteraciones neurológicas, insuficiencia hepática y toxicomanías (9).

El SA tiene una incidencia estimada en 1,9 a 9,4\% de los pacientes sometidos a anestesia general y 3,3\% después de anestesia regional. Existen tres principales áreas en las que se presenta SA como después de anestesia, tratamientos psiquiátricos o por intoxicación por fármacos u drogas con propiedad anticolinérgicas (9).

El tratamiento consiste en protección de la vía aérea, apoyo hemodinámico, monitorización cardiorrespiratoria, electrocardiográfica y lavado gástrico (9). Uso de carbón activado para bloquear la absorción del medicamento ingerido y benzodiazepinas para el manejo de agitación y crisis convulsivas. El lavado gástrico y el carbón activado son útiles en las primeras 2 horas posterior a la ingesta del tóxico, pero podrían utilizarse hasta las primeras 24 horas, ya que el efecto anticolinérgico reduce el peristaltismo gastrointestinal (10).

El salicilato de fisostigmina se ha utilizado con eficacia para este síndrome tóxico desde la década de 1970, a pesar de la controversia por sus efectos adversos, es ampliamente aceptado como antídoto para el SA $(11,12)$. Su uso se prefiere para casos severos por compromiso del sistema nervioso central, teniendo en cuenta su contraindicación en pacientes con prolongación del complejo QRS y QTc $(10,13)$. Se recomienda una dosis de $0,02 \mathrm{mg} / \mathrm{kg}$ de fisostigmina (rango 0,5$2 \mathrm{mg}$ ) pasarlos en 2 minutos usando un acceso venoso periférico, reevaluando periódicamente el estado neurológico. Esto se puede repetir cada 10 minutos si es necesario, hasta un máximo de $4 \mathrm{mg}$. Los efectos adversos de la fisostigmina son de naturaleza colinérgica (diaforesis, emesis, diarrea, incontinencia urinaria, broncorrea, bradicardia) y aparecen 10-20 minutos después de la administración, o cuando se produce efecto pico en sistema nervioso central $(14,15)$.

La Intoxicación por floripondio ocasionó un síndrome anticolinérgico (SA) manifiesto en el paciente con midriasis, palpitaciones, taquicardia, confusión, alucinaciones y una crisis convulsiva, que resolvió en poco tiempo y sin requerir medidas farmacológicas.

La intoxicación por floripondio es una de las intoxicaciones por plantas que representan de un 5 a $10 \%$ de todas las consultas recibidas en centros toxicológicos y sólo algunas pueden provocar la muerte (16).

Las plantas con efectos alucinógenos, son una problemática creciente, ya que su uso recreativo viene en ascenso, principalmente en población joven, quienes subvaloran el gran riesgo para la salud. A pesar de que se requieren más estudios acerca de los efectos de estas plantas, son varios los reportes que mencionan un importante grado de toxicidad y riesgo de complicaciones neurológicas. El floripondio por su amplia distribución en el territorio nacional, la no regularización y el fácil acceso, se postula a futuro como un problema de salud pública en la población consumidora de sustancias psicoactivas.

\section{Conflicto de intereses:}

Los autores declaran no tener conflicto de intereses.

\section{Referencias:}

1. Roses O, Lopez C, Garcia J. Aislamiento e identificación de alcaloides del tropano en especies del género Brugmansia (Solanaceae). Acta Farm. Bonaerense 1987; 6 (3): 167-174.

2. Armijos C, Cota L, Gonzales S. Traditional medicine applied by the Saraguro yachakkuna: a preliminary approach to the use of sacred and psychoactive plant species in the southern region of Ecuador. J Ethnobiol Ethnomed 2014; 10:26

3. Plenert B, Prasa D, Hentschel H, Deters M. Plant Exposures Reported to the Poisons Information Centre Erfurt from 20012010. Planta Med 2012; 78: 401-408 
4. Kim Y, Kim J, Joon O, Chan W. Intoxication by angel's trumpet: case report and literature review. BMC Research Notes 2014; 7:553.

5. Arteaga L, Perea M, Reguero M. Brugmansia: una especie promisoria para los alcaloides del tropano. Rev. colomb. cienc. quim. farm. 1993; 21: 36-40.

6. Nencini C, Cavallo F, Bruni G, Capasso A, De Feo V, De Martino L, Giorgi G, Micheli L. Affinity of Iresine herbstii and Brugmansia arborea extracts on different cerebral receptors. J. Ethnopharmacol. 2006; 105 (3):352-357.

7. Capasso A, De Feo V. In vitro binding receptors study by Valeriana adscendens, Iresine herbstii and Brugmansia arborea extracts. Med. Chem. 2007; 3 (6): 599-604.

8. Carrillo R, Ramírez F, Garnica M, Méndez J, Esquivel S, Rocha M, Carrillo C. Síndrome anticolinérgico. Rev Invest Med Sur Mex 2012; 19(4): 244-249.

9. Gómez J, Gutiérrez M, Colunga A, Santoyo N. Síndrome anticolinérgico central: Reporte de dos casos. Rev Mex Anest 2003; 26 (1): 25-27.

10. Diker D, Markovitz D, Rohtman M, Sendovski U. Coma as a presenting sign of Datura stramonium seed tea poisoning. Eur. J. of Intern. Med. 2007; 18: 336-338.

11. Watkins J, Schwarz E, Arroyo A, Mullins M. The Use of Physostigmine by Toxicologists in Anticholinergic Toxicity. J Med Toxicol 2015; 11(2): 179-184.

12. Dart RC, Borron SW, Caravati EM, Cobaugh DJ, Curry SC, Falk JL, Goldfrank L, Gorman SE, Groft S, et al. Expert consensus guidelines for stocking of antidotes in hospitals that provide emergency care. Ann Emerg Med 2009;54(3): 386-394.e1.

13. Benowitz I, Cohen AR, Glykys J, Gorstein S, Burns M, Miller E. An altered, unresponsive teenager in the emergency department. J. Emer. Med. 2016; 50(1): 116-120.

14. Moore PW, Rasimas J, Donovan JW. Physostigmine is the Antidote for Anticholinergic Syndrome. J Med Toxicol 2015; 11(1): 159-160.

15. Glatstein M, Alabdulrazzaq F, Garcia F, Scolnik D. Use of Physostigmine for Hallucinogenic Plant Poisoning in a Teenager: Case Report and Review of Literature. Am J Ther 2012; 19(5): 384-388.

16. Perez E, Rodriguez R, Sanchez M. Plantas tóxicas: Neurotoxicidad por floripondio, reporte de caso. Arch Med Urgen Méx 2012; 4(3): 119-124. 